\title{
Melhoria ergonômica em postos de trabalho do setor de acabamento de uma fundição através do método OWAS de análise de posturas
}

Natália Fernanda Santos Pereira

natsantos23@gmail.com

Gilson Marques Pinheiro

gilsonmarques1@gmail.com

Daniela Araújo Viriato

danielaav00@ hotmail.com

Eriane Cristine da Fonseca Silva

erianecristine@gmail.com

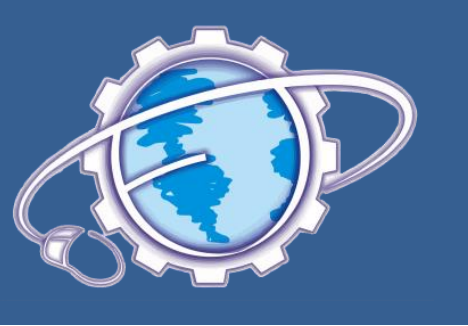

\section{RESUMO}

O setor de acabamento de uma fundição é caracterizado por um ambiente que apresenta trabalho pesado. Na empresa pesquisada, posturas e movimentos inadequados utilizados para manusear as lixadeiras e peças fundidas apresentam riscos à saúde do trabalhador ligados às condições atuais de trabalho. Nesse sentido, foi realizada análise ergonômica em dois postos de trabalho daquele setor, denominados linha carrossel $e$ mercado interno. Para tanto, utilizou-se a metodologia OWAS para análise das posturas que estavam causando desconforto aos operadores. Como resultado foi constatado que 33\% das posturas adotadas na linha carrossel eram críticas - classes 3 e 4 -, indicando a necessidade de mudança das posturas no curto prazo. Já no mercado interno $14 \%$ das posturas foram categorizadas como classe 3, que são claramente prejudiciais à saúde dos trabalhadores. Para melhorar a adaptação da tarefa de esmerilhamento de peças fundidas à capacidade física dos operadores, foi recomendada a aquisição de bancada regulável pneumática, a confecção de dispositivo para posicionamento das peças e a utilização de talha pneumática para movimentação das peças, além do treinamento e conscientização dos operadores. Essas recomendações possibilitaram redução de $100 \%$ das posturas críticas de trabalho.

Palavras-chave: Método OWAS, Postura, Fundição, Acabamento.

\section{Ergonomic improvement at job sites in the finishing sector of a foundry through the OWAS method of posture analysis}

\begin{abstract}
The finishing sector of a foundry is characterized by an environment which presents heavy work. In the researched company, inappropriate postures and movements used to handle the sanders and casting present risks to the worker's health related to the current conditions of the job. Thus, an ergonomic analysis was conducted in two sites of that sector, denominated carrousel line and internal market. For such, the OWAS methodology was applied to analyze the postures which were causing discomfort to the operating workers. The results demonstrated that 33\% of the adopted postures in the carrousel line were critical - classes 3 and 4 -, indicating a need to change the postures in the short run. On the other hand, $14 \%$ of the postures in the internal market were categorized as class 3, which is clearly harmful to the workers' health. In order to improve the adaptation of the fettling task the casting to the workers' physical capacity, it was recommended the acquisition of an adjustable pneumatic balcony, the confection of a device to place the material and the use of a pneumatic carving to move the pieces, in addition to the workers' training and awareness. These recommendations made it possible to reduce the postures critical to work by $100 \%$.
\end{abstract}

Key words: OWAS Method; Posture; Foundry; Finishing. 


\section{Introdução}

A operação de esmerilhar uma peça fundida tem a finalidade de retirar rebarbas e inclusões superficiais aderidas a ela no processo de resfriamento do metal. Essa operação atribui à peça um acabamento mais fino, uma textura mais lisa, um melhor aspecto visual e estético e eleva a capacidade de aderência e fixação de tinta, quando necessário.

O setor de acabamento da empresa pesquisada é subdividido em boxes para o acabamento superficial das peças. No total são 32 boxes divididos entre as áreas chamadas de mercado interno, carrossel I e II, linha IV e o esmeril, em que são executadas as tarefas por um operador com a utilização de lixadeiras.

O trabalho de esmerilhamento é realizado em pé, com a utilização dos membros superiores (braços e mãos). Porém, em alguns instantes e devido à falta de um dispositivo para posicionar a peça, o operador faz vários movimentos, curvando a coluna cervical. Também no momento de posicionamento da peça, ele realiza levantamento de carga, além do peso da esmerilhadeira ( $8 \mathrm{~kg})$, que segura durante todo o trabalho. Somente nos intervalos de posicionamento da peça para iniciar a operação e retirar a peça do posto de trabalho é que o operador descansa do peso da esmerilhadeira.

Neste estudo foram considerados somente os postos de trabalho que executam o acabamento da parte externa da peça, sendo um posto do mercado interno e um posto da linha carrossel I.

Para tanto, foi utilizado o método OWAS (Ovako Working Posture Analysing System) para estudar as principais posturas adotadas na realização da atividade e identificar aquelas mais impactantes à saúde dos trabalhadores, de forma a implementar ações para a melhoria das condições de trabalho.

\section{Conceitos básicos e fundamentação teórica}

\subsection{Ergonomia}

Vários cientistas definiram ergonomia de acordo com suas concepções. No entanto, todas têm o mesmo entendimento que é o uso multidisciplinar de avaliação do trabalho para o homem e a ação de análise e melhoria da situação de trabalho envolvida (IIDA, 2005).
Laville (1977) definiu ergonomia como um conjunto de conhecimentos que visam ao desempenho do homem em certa atividade, a fim de aplicá-los à concepção das tarefas, dos instrumentos, das máquinas e dos sistemas de produção.

A ergonomia "é o conjunto de conhecimentos científicos relativos ao homem e necessários para a concepção de ferramentas, máquinas e dispositivos que possam ser utilizados com o máximo de conforto, segurança e eficácia" (WISNER, 1987, p. 12).

\subsection{Análise de postura do corpo humano}

Segundo Guérin et al. (2001, p. 152), "as posturas constituem um indicador complexo da atividade e dos constrangimentos que pesam sobre ela. São também um objeto de estudo em si, na medida em que são fontes de fadiga e podem gerar distúrbios vertebrais, articulares etc.".

Iida (2005, p. 165) definiu três situações principais, em que a má postura pode produzir consequências danosas: "trabalhos estáticos que envolvem uma postura parada por longos períodos; trabalhos que exigem muita força e trabalhos que exigem posturas desfavoráveis, como o tronco inclinado e torcido".

Conforme Iida (2005), um dos métodos utilizados para avaliação da carga postural durante o trabalho é o método OWAS, que se baseia na observação, no registro, na classificação e na análise da postura de trabalho. Esse método foi desenvolvido por pesquisadores finlandeses, em 1977, que trabalhavam em uma empresa siderúrgica realizando análises fotográficas das principais posturas encontradas na indústria pesada. Foram registradas 72 posturas típicas, resultando em diferentes combinações das posições do dorso (quatro posições típicas), braços (três posições típicas) e pernas (sete posições típicas). Essas posições estão relacionadas na Figura 1. 


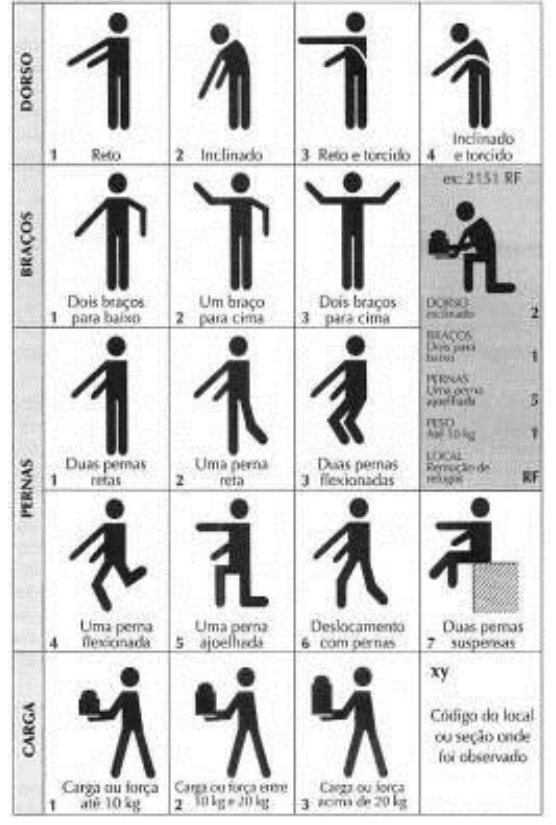

Figura 1 - Sistema OWAS

Fonte: IIDA, 2005. p. 170.

Segundo o método OWAS, a classificação da postura é feita de acordo com a combinação das variáveis dorso, braços, pernas e carga, conforme ilustrado no Quadro 1.

\begin{tabular}{|c|c|c|c|c|c|c|c|c|c|c|c|c|c|c|c|c|c|c|c|c|c|c|}
\hline \multirow{4}{*}{ DORSO } & \multirow{4}{*}{ BRAÇO } & \multicolumn{21}{|c|}{ PERNAS } \\
\hline & & \multicolumn{3}{|c|}{1} & \multicolumn{3}{|c|}{2} & \multicolumn{3}{|c|}{3} & \multicolumn{3}{|c|}{4} & \multicolumn{3}{|c|}{5} & \multicolumn{3}{|c|}{6} & \multicolumn{3}{|c|}{7} \\
\hline & & \multicolumn{21}{|c|}{ CARGA } \\
\hline & & 1 & 2 & 3 & 1 & 2 & 3 & 1 & 2 & 3 & 1 & 2 & 3 & 1 & 2 & 3 & 1 & 2 & 3 & 1 & 2 & \\
\hline \multirow{3}{*}{1} & 1 & 1 & 1 & 1 & 1 & 1 & 1 & 1 & 1 & 1 & 2 & 2 & 2 & 2 & 2 & 2 & 1 & 1 & 1 & 1 & 1 & 1 \\
\hline & 2 & 1 & 1 & 1 & 1 & 1 & 1 & 1 & 1 & 1 & 2 & 2 & 2 & 2 & 2 & 2 & 1 & 1 & 1 & 1 & 1 & 1 \\
\hline & 3 & 1 & 1 & 1 & 1 & 1 & 1 & 1 & 1 & 1 & 2 & 2 & 3 & 2 & 2 & 3 & 1 & 1 & 1 & 1 & 1 & 2 \\
\hline \multirow{3}{*}{2} & 1 & 2 & 2 & 3 & 2 & 2 & 3 & 2 & 2 & 3 & 3 & 3 & 3 & 3 & 3 & 3 & 2 & 2 & 2 & 2 & 3 & 3 \\
\hline & 2 & 2 & 2 & 3 & 2 & 2 & 3 & 2 & 3 & 3 & 3 & 4 & 4 & 3 & 4 & 4 & 3 & 3 & 4 & 2 & 3 & 4 \\
\hline & 3 & 3 & 3 & 4 & 2 & 2 & 3 & 3 & 3 & 3 & 3 & 4 & 4 & 4 & 4 & 4 & 4 & 4 & 4 & 2 & 3 & 4 \\
\hline \multirow{3}{*}{3} & 1 & 1 & 1 & 1 & 1 & 1 & 1 & 1 & 1 & 2 & 3 & 3 & 3 & 4 & 4 & 4 & 1 & 1 & 1 & 1 & 1 & 1 \\
\hline & 2 & 2 & 2 & 3 & 1 & 1 & 1 & 1 & 1 & 2 & 4 & 4 & 4 & 4 & 4 & 4 & 3 & 3 & 3 & 1 & 1 & 1 \\
\hline & 3 & 2 & 2 & 3 & 1 & 1 & 1 & 2 & 3 & 3 & 4 & 4 & 4 & 4 & 4 & 4 & 4 & 4 & 4 & 1 & 1 & 1 \\
\hline & 1 & 2 & 3 & 3 & 2 & 2 & 3 & 2 & 2 & 3 & 4 & 4 & 4 & 4 & 4 & 4 & 4 & 4 & 4 & 2 & 3 & 4 \\
\hline & 2 & 3 & 3 & 4 & 2 & 3 & 4 & 3 & 3 & 4 & 4 & 4 & 4 & 4 & 4 & 4 & 4 & 4 & 4 & 2 & 3 & 4 \\
\hline & 3 & 4 & 4 & 4 & 2 & 3 & 4 & 3 & 3 & 4 & 4 & 4 & 4 & 4 & 4 & 4 & 4 & 4 & 4 & 2 & 3 & 4 \\
\hline
\end{tabular}

Quadro 1 - Classificação das posturas pela combinação das variáveis

Fonte: IIDA, 2005.

Ainda de acordo com Iida (2005), a identificação da classe depende também do tempo de duração das posturas, conforme ilustrado no Quadro 2.

\begin{tabular}{|c|c|c|c|c|c|c|c|c|c|c|c|}
\hline \multicolumn{2}{|r|}{$\begin{array}{l}\text { DURAÇÃO MÁXIMA } \\
\text { (\% da jornada de trabalho) }\end{array}$} & 10 & 20 & 30 & 40 & 50 & 60 & 70 & 80 & 90 & 100 \\
\hline \multirow{4}{*}{ DORSO } & 1. Dorso reto & 1 & 1 & 1 & 1 & 1 & 1 & 1 & 1 & 1 & 1 \\
\hline & 2. Dorso inclinado & 1 & 1 & 1 & 2 & 2 & 2 & 2 & 2 & 3 & 3 \\
\hline & 3. Dorso reto e torcido & 1 & 1 & 2 & 2 & 2 & 3 & 3 & 3 & 3 & 3 \\
\hline & 4. Inclinado e torcido & 1 & 2 & 2 & 3 & 3 & 3 & 3 & 4 & 4 & 4 \\
\hline \multirow{3}{*}{ BRAÇOS } & 1. Dois braços para baixo & 1 & 1 & 1 & 1 & 1 & 1 & 1 & 1 & 1 & 1 \\
\hline & S 2 . Um braço para cima & 1 & 1 & 1 & 2 & 2 & 2 & 2 & 2 & 3 & 3 \\
\hline & 3. Dois braços para cima & 1 & 1 & 2 & 2 & 2 & 2 & 2 & 3 & 3 & 3 \\
\hline \multirow{7}{*}{ PERNAS } & 1. Duas pernas retas & 1 & 1 & 1 & 1 & 1 & 1 & 1 & 1 & 1 & 2 \\
\hline & 2. Uma perna reta & 1 & 1 & 1 & 1 & 1 & 1 & 1 & 1 & 2 & 2 \\
\hline & 3. Duas pernas flexionadas & 1 & 1 & 1 & 2 & 2 & 2 & 2 & 2 & 3 & 3 \\
\hline & 4. Uma perna flexionada & 1 & 2 & 2 & 3 & 3 & 3 & 3 & 4 & 4 & 4 \\
\hline & 5. Uma perna ajoelhada & 1 & 2 & 2 & 3 & 3 & 3 & 3 & 4 & 4 & 4 \\
\hline & 6. Deslocamento com as pernas & 1 & 1 & 2 & 2 & 2 & 3 & 3 & 3 & 3 & 3 \\
\hline & 7. Duas pernas suspensas & 1 & 1 & 1 & 1 & 1 & 1 & 1 & 1 & 2 & 2 \\
\hline
\end{tabular}

Quadro 2 - Classificação das posturas de acordo com a duração

Fonte: IIDA, 2005. p. 171.

Conforme a combinação das posições do dorso, braços, pernas e carga, segundo Iida (2005, p. 171), as posturas são classificadas da seguinte forma:

a) Classe 1 - postura normal, que dispensa cuidados, a não ser em casos excepcionais.

b) Classe 2 - postura que deve ser verificada durante a próxima revisão.

c) Classe 3 - postura que deve merecer atenção no curto prazo.

d) Classe 4 - postura que deve merecer atenção imediata.

\section{Metodologia}

Foi realizada pesquisa científica de natureza aplicada, com o objetivo de gerar conhecimentos para melhorar as condições de trabalho dos operadores do setor de acabamento de uma fundição.

Esta pesquisa trata de um estudo de caso que teve abordagens qualitativa e quantitativa. A coleta de dados e informações referentes à situação de trabalho realizou-se através de entrevistas, fotografias, observações e filmagens na área de trabalho. Especificamente, foram utilizados na coleta de dados: câmera fotográfica digital para gravação das posturas e movimentos realizados durante a jornada de trabalho e posterior observação, questionário "Censo de Ergonomia" para coleta de informações referentes à opinião e sentimento dos trabalhadores a respeito do trabalho e trena para verificar as medidas do posto de trabalho.

As posturas dos operadores foram 
observadas, registradas, classificadas e interpretadas segundo o método OWAS, de forma a possibilitar a implementação de ações para melhorar as condições de trabalho e, dessa maneira, eliminar a necessidade de adoção de posturas desfavoráveis.

O questionário aplicado foi respondido por 50 operadores do setor, o que representa $60 \%$ do total de operadores.

\section{Contextualizando a atividade de acabamento de peças}

As peças acabadas no setor de acabamento apresentam um ciclo de operações, conforme detalhado na Figura 2.

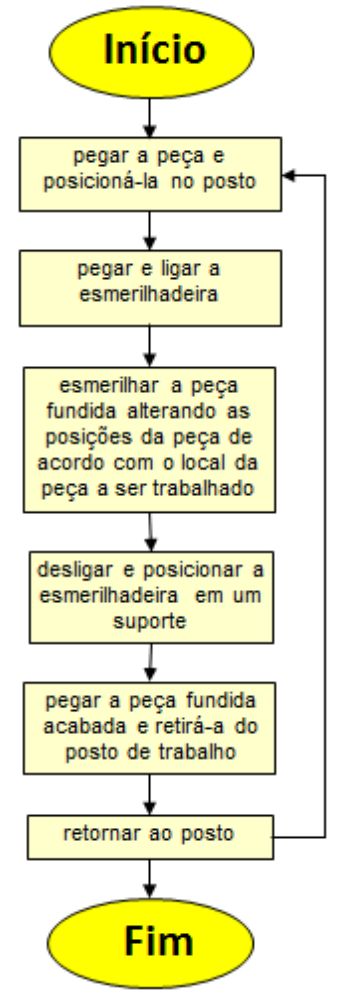

Figura 2 - Ciclo de operações realizadas nos postos de trabalho do setor de acabamento

\section{Análise das posturas utilizando o método OWAS}

O resultado da aplicação do questionário "Censo de ergonomia" indicou que 78\% dos operadores sentem desconforto, sendo a coluna a região do corpo mais afetada, e que para $59 \%$ dos operadores esse desconforto aumenta durante a jornada normal de trabalho.

As posturas dos operadores, na rotina do trabalho de acabamento de peças, foram analisadas nos dois postos, mercado interno e linha carrossel, conforme o método OWAS. Através de filmagem, podem-se congelar algumas imagens de posições durante o ciclo de trabalho e classificar as posturas através da combinação das variáveis dorso, braços, pernas e carga, conforme detalhado nas Figuras 3 a 18 e na Tabela 1.

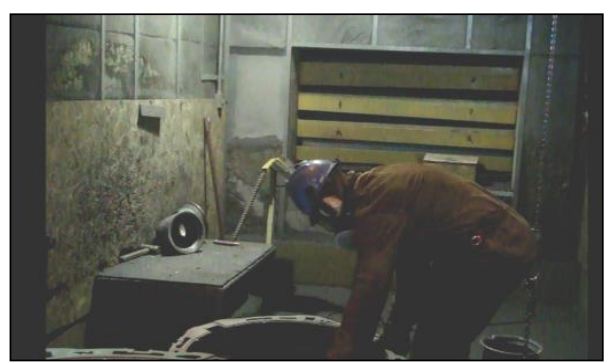

Figura 3 - Postura 1: operador pegando a peça para posicionála no posto de trabalho mercado interno.

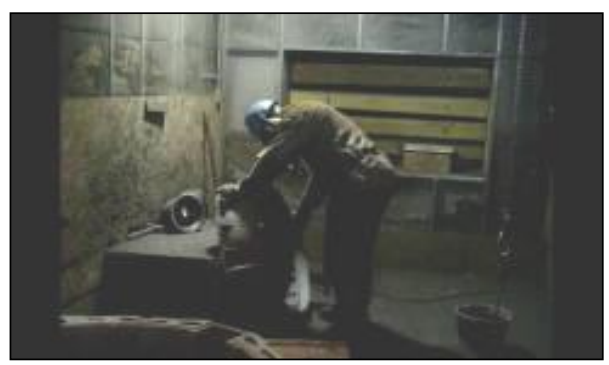

Figura 4 - Postura 2: operador posicionando a peça no posto de trabalho mercado interno.

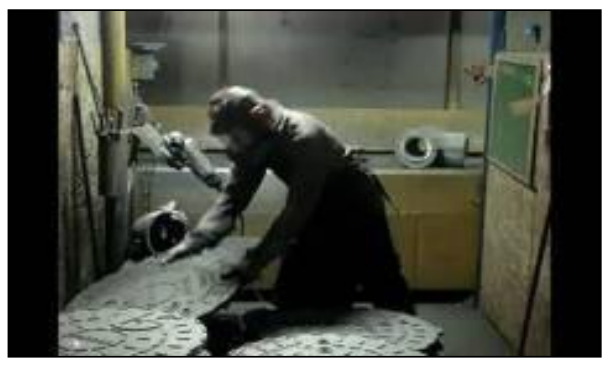

Figura 5 - Postura 3: operador pegando a peça para posicionála no posto de trabalho linha carrossel.

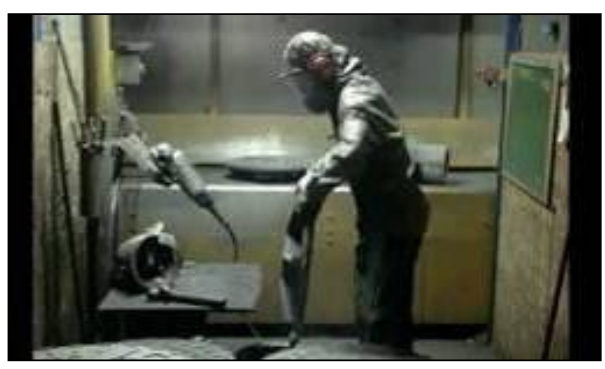

Figura 6 - Postura 4: operador posicionando a peça para iniciar atividade de acabamento.

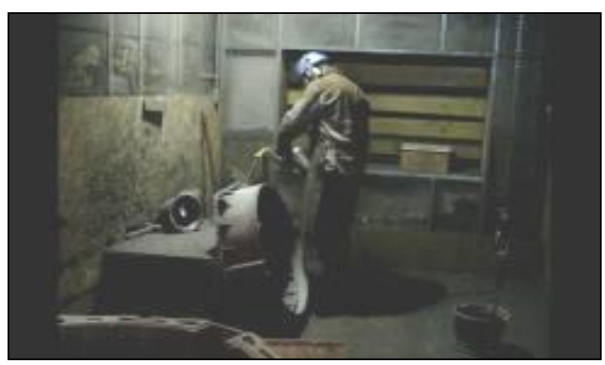

Figura 7 - Postura 5: operador pegando e ligando a lixadeira no posto de trabalho mercado interno. 


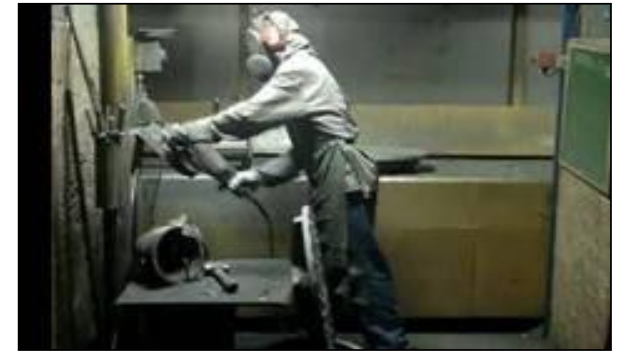

Figura 8 - Postura 6: operador pegando e ligando a lixadeira no posto de trabalho linha carrossel.

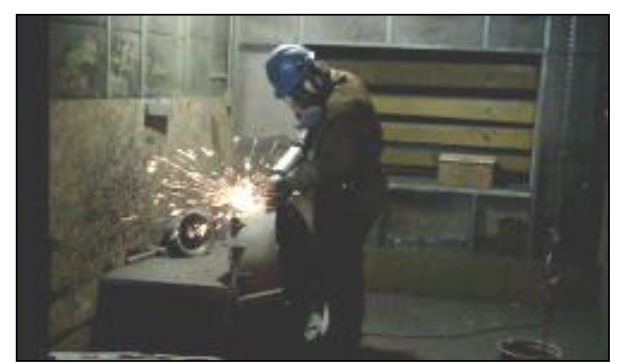

Figura 9 - Postura 7: início do esmerilhamento da peça no posto de trabalho mercado interno

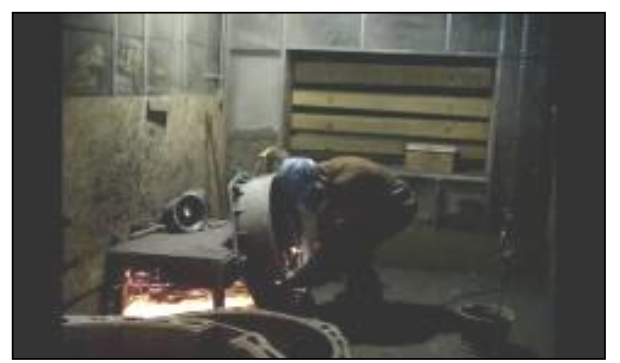

Figura 10 - Postura 8: esmerilhamento da parte lateral da peça no posto de trabalho mercado interno.

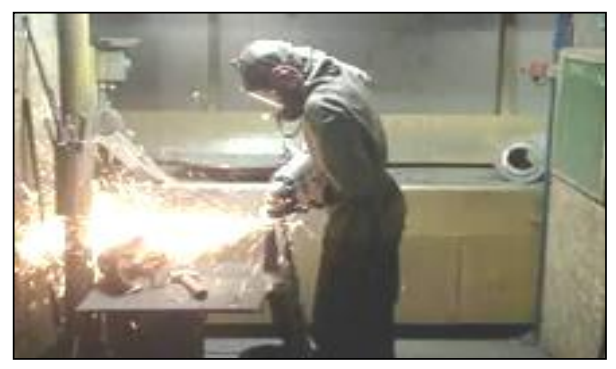

Figura 11 - Postura 9: início do esmerilhamento da peça no posto de trabalho linha carrossel

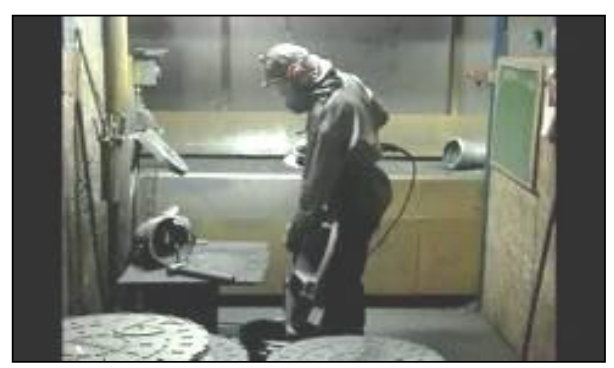

Figura 12 - Postura 10: girando a peça para acabar outras faces na linha carrossel

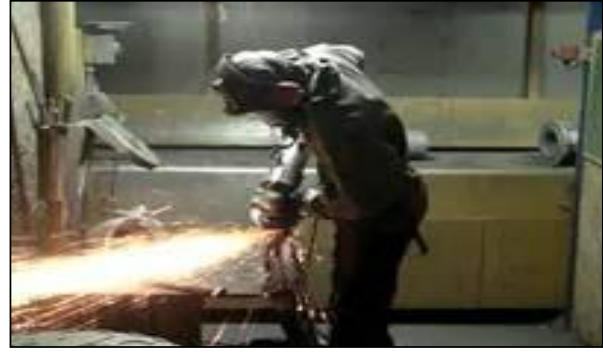

Figura 13 - Postura 11: retorna ao esmerilhamento após mudar a posição da peça na linha carrossel

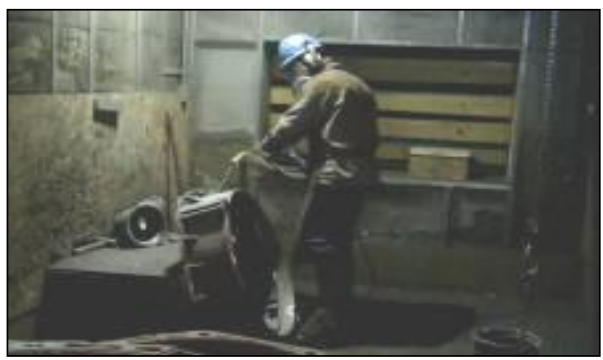

Figura 14 - Postura 12: operador desligando e posicionando a lixadeira no suporte no posto de trabalho mercado interno

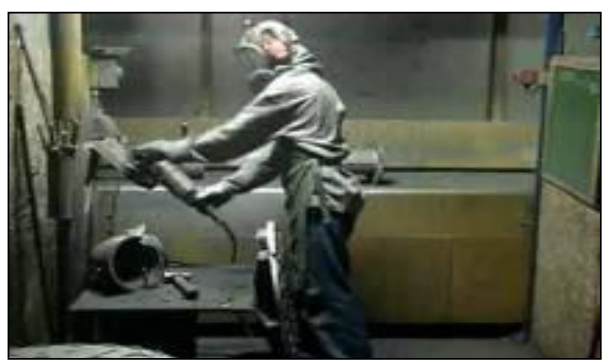

Figura 15 - Postura 13: operador desligando próximo posto de trabalho

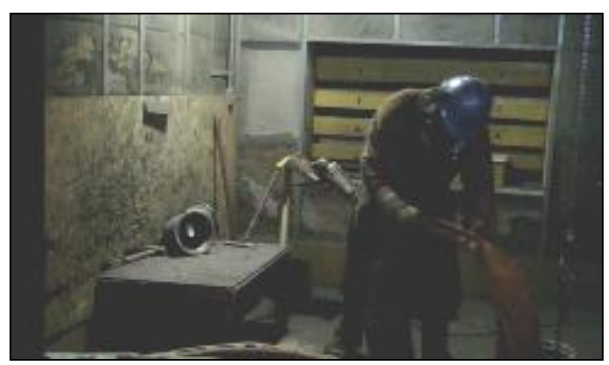

Figura 16 - Postura 14: operador rolando a peça posicionando a lixadeira no suporte no posto para o mercado interno

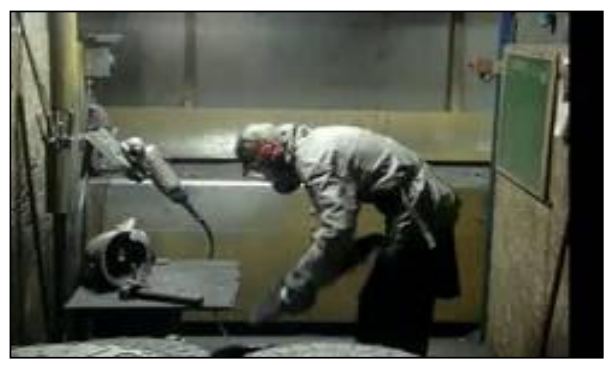

Figura 17 - Postura 15: operador pega a peça e posiciona na esteira na linha carrossel 


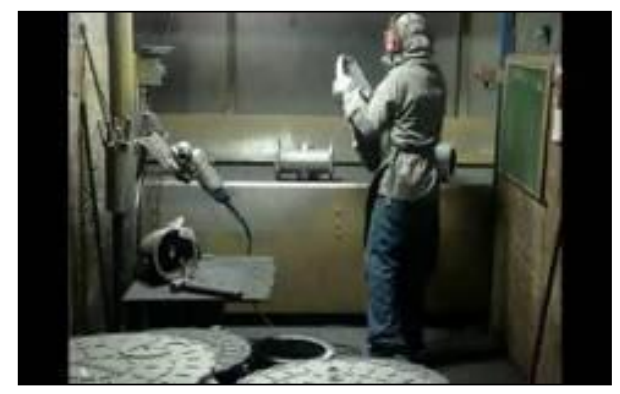

Figura 18 - Postura 16: operador posiciona a acabada peça na esteira ao lado direito da linha carrossel

Tabela 1- Classificação das posturas pelo método OWAS

\begin{tabular}{|c|c|c|c|c|c|c|c|}
\hline $\begin{array}{c}\text { POSTO DE } \\
\text { TRABALHO }\end{array}$ & OPERAÇÕES & POSTURA & FATORES & ÍNDICE & CLASSE & CLASSE & Ação \\
\hline \multirow{28}{*}{ 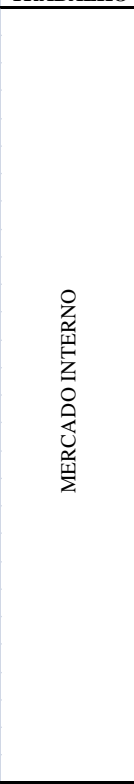 } & \multirow{4}{*}{$\begin{array}{c}\text { Pegar a peça do palete } \\
\text { para posicioná-la no } \\
\text { posto de trabalho. }\end{array}$} & \multirow{4}{*}{1} & DORSO: Inclinado & 2 & \multirow{4}{*}{3} & \multirow{4}{*}{$\begin{array}{l}\text { Claramente } \\
\text { prejudicial }\end{array}$} & \multirow{4}{*}{$\begin{array}{c}\text { Mudar } \\
\text { postura a } \\
\text { curto prazo }\end{array}$} \\
\hline & & & BRACOS: Dois braços para baixo & 1 & & & \\
\hline & & & PERNAS: Duas pernas flexionadas & 3 & & & \\
\hline & & & \begin{tabular}{|l|} 
CARGA: Peso da peça $59 \mathrm{kgs}$ \\
\end{tabular} & 3 & & & \\
\hline & \multirow{4}{*}{$\begin{array}{c}\text { Operador } \\
\text { posicionando a peça } \\
\text { no posto de trabalho }\end{array}$} & \multirow{4}{*}{2} & DORSO: Inclinado & 2 & \multirow{4}{*}{2} & \multirow{4}{*}{$\begin{array}{l}\text { Levemente } \\
\text { prejudicial }\end{array}$} & \multirow{4}{*}{$\begin{array}{c}\text { Verificar } \\
\text { postura na } \\
\text { próxima } \\
\text { revisão }\end{array}$} \\
\hline & & & BRAÇOS: Dois braços para baixo & 1 & & & \\
\hline & & & PERNAS: Uma perna reta & 2 & & & \\
\hline & & & CARGA: Força até $10 \mathrm{Kg}$ & 1 & & & \\
\hline & \multirow{4}{*}{$\begin{array}{l}\text { Operador pegando e } \\
\text { ligando a lixadeira }\end{array}$} & \multirow{4}{*}{5} & DORSO: Inclinado & 2 & & & Verificar \\
\hline & & & BRAÇOS: Dois braços para baixo & 1 & 2 & Levemente & postura na \\
\hline & & & PERNAS: Duas pernas retas & 1 & 2 & prejudicial & próxima \\
\hline & & & CARGA: Peso da esmerihadeira $8 \mathrm{kgs}$ & 1 & & & revisão \\
\hline & Início do & & DORSO: Inclinado & 2 & & & Verificar \\
\hline & esmerilhamento da & & BRAÇOS: Dois braços para baixo & 1 & 2 & Levemente & postura na \\
\hline & peça no posto de & 7 & \begin{tabular}{|l|} 
PERNAS: Duas pernas retas \\
\end{tabular} & 1 & 2 & prejudicial & próxima \\
\hline & trabalho & & CARGA: Peso da esmerihadeira $8 \mathrm{kgs}$ & 1 & & & revisão \\
\hline & & & DORSO: Inclinado & 2 & & & Verificar \\
\hline & Esmerunamento da & 8 & BRAÇOS: Dois braços para baixo & 1 & 2 & Levemente & postura na \\
\hline & parte miterna laterar da & 8 & PERNAS: Duas pernas flexionadas & 3 & 2 & prejudicial & próxima \\
\hline & & & CARGA: Peso da esmerihadeira $8 \mathrm{kgs}$ & 1 & & & revisão \\
\hline & & & DORSO: Inclinado & 2 & & & Verificar \\
\hline & Uperador desigando e & 12 & BRAÇOS: Dois braços para baixo & 1 & 2 & Levemente & postura na \\
\hline & $\begin{array}{c}\text { posicionando a } \\
\text { Jixadeira no }\end{array}$ & 12 & PERNAS: Duas pernas retas & 1 & 2 & prejudicial & próxima \\
\hline & & & CARGA: Peso da esmerihadeira $8 \mathrm{kgs}$ & 1 & & & revisão \\
\hline & Operador rolando a & & DORSO: Inclinado & 2 & & & Verificar \\
\hline & peça acabada para o & 10 & BRAÇOS: Dois braços para baixo & 1 & 0 & Levemente & postura na \\
\hline & próximo posto de & 14 & PERNAS: Deslocamento com pernas & 6 & 2 & prejudicial & próxima \\
\hline & trabalho & & CARGA: Peso da peça 59 kgs & 3 & & & revisão \\
\hline & & & DORSO: Inclinado e torcido & 4 & & & \\
\hline & Pegar a peça do palete & 3 & BRAÇOS: Dois braços para baixo & 1 & 4 & Extremamente & postura \\
\hline & para posiciona-la no & & PERNAS: Deslocamento com pernas & 6 & 4 & prejudicial & imediatamen \\
\hline & & & CARGA: Peso da peça $28,6 \mathrm{Kg}$ & 3 & & & $\mathrm{e}$ \\
\hline & & & DORSO: Inclinado & 2 & & & Verificar \\
\hline & Operador & 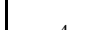 & BRAÇOS: Dois braços para baixo & 1 & 0 & Levemente & postura na \\
\hline & posicionando a peça & 4 & PERNAS: Duas pernas reta & 1 & 2 & prejudicial & próxima \\
\hline & & & CARGA: Força até $10 \mathrm{kgs}$ & 1 & & & revisão \\
\hline & & & DORSO: Inclinado & 2 & & & Verificar \\
\hline & Operador pegando e & 6 & BRAÇOS: Dois braços para baixo & 1 & 2 & Levemente & postura na \\
\hline & ligando a lixadeira & 0 & PERNAS: Duas pernas retas & 1 & 2 & prejudicial & próxima \\
\hline & & & CARGA: Peso da esmerihadeira $8 \mathrm{kgs}$ & 1 & & & revisão \\
\hline & Início do & & DORSO: Inclinado & 2 & & & Verificar \\
\hline & esmerilhamento da & 9 & BRAÇOS: Dois braços para baixo & 1 & 2 & Levemente & postura na \\
\hline & peça no posto de & & PERNAS: Duas pernas retas & 1 & & prejudicial & próxima \\
\hline & trabalho & & CARGA: Peso da esmerihadeira $8 \mathrm{kgs}$ & 1 & & & revisão \\
\hline s & & & DORSO: Inclinado & 2 & & & \\
\hline$\frac{\pi}{x}$ & Girando a peça para & & BRAÇOS: Dois braços para baixo & 1 & & & Mudar \\
\hline$\frac{2}{4}$ & esmerilhamento de & 10 & PERNAS: Duas pernas retas & 1 & 3 & Claramente & postura a \\
\hline 起 & outras faces & & $\begin{array}{l}\text { CARGA: Média do peso da esmerihadeira } 8 \\
\text { Kgs e da peça } 28,6 \text { Kgs. }\end{array}$ & 3 & & & curto prazo \\
\hline 当 & Retorna ao & & DORSO: Inclinado e torcido & 4 & & & Verificar \\
\hline & esmerilhalmento após & 11 & BRAÇOS: Dois braços para baixo & 1 & 0 & Levemente & postura na \\
\hline & mudar a posição da & 11 & PERNAS: Duas pernas retas & 1 & 2 & prejudicial & próxima \\
\hline & peça & & CARGA: Peso da esmerihadeira $8 \mathrm{kgs}$ & 1 & & & revisão \\
\hline & & & DORSO: Inclinado e torcido & 4 & & & Verificar \\
\hline & Operador desligando e & 13 & BRAÇOS: Dois braços para baixo & 1 & 2 & Levemente & postura na \\
\hline & posicionando a & & PERNAS: Uma perna reta & 2 & & prejudicial & próxima \\
\hline & & & CARGA: Peso da esmerihadeira $8 \mathrm{kgs}$ & 1 & & & revisão \\
\hline & & & DORSO: Inclinado & 2 & & & \\
\hline & Operador pega a peça & 15 & BRAÇOS: Dois braços para baixo & 1 & 3 & Claramente & Mudar \\
\hline & posicionar para & & PERNAS: Duas pernas flexionadas & 3 & & prejudicial & postura a \\
\hline & & & CARGA: Peso da peça $28,6 \mathrm{Kg}$ & 3 & & & \\
\hline & & & DORSO: Reto & 1 & & & \\
\hline & Operador posiciona a & 16 & BRAÇOS: Dois braços para baixo & 1 & 1 & Normol & Nenbump \\
\hline & peça na esteira & 16 & PERNAS: Deslocamento com pernas & 6 & 1 & Normal & Nenhuma \\
\hline & & & CARGA: Peso da peça $28,6 \mathrm{Kg}$ & 3 & & & \\
\hline
\end{tabular}




\section{Conforme avaliação das posturas pelo} método OWAS, sintetizada na Tabela 1, é necessária a mudança de algumas posturas assumidas pelos operadores dos postos de trabalho: mercado interno e linha carrossel. Demandam ações, no curto prazo, das posturas que exigem levantamento de carga ou execução de força, como a tarefa de pegar a peça para posicioná-la no posto de trabalho, girá-la para esmerilhar as faces e pegar a peça para posicioná-la na esteira. É necessária mudança imediata na postura da tarefa de pegar a peça para posicioná-la no posto de trabalho na linha carrossel. As demais posições assumidas na execução das tarefas requerem verificação em uma próxima revisão.

\section{Recomendações e ações de melhoria}

Para possibilitar a melhoria das posturas, foi confeccionado um dispositivo regulável, conforme ilustrado nas Figuras 19 e 20, para encaixe da peça de forma a evitar a inclinação do dorso do operador durante a execução da atividade e também facilitar a rotação da peça para o acabamento das faces. As peças deverão ser posicionadas no dispositivo através de talhas pneumáticas, evitando que o operador force a região da coluna quando pega a peça para posicioná-la no posto de trabalho. Estando as peças posicionadas no dispositivo, não há necessidade de o operador inclinar o corpo para posicionar as peças na esteira da linha carrossel, eliminando-se o levantamento de peso.

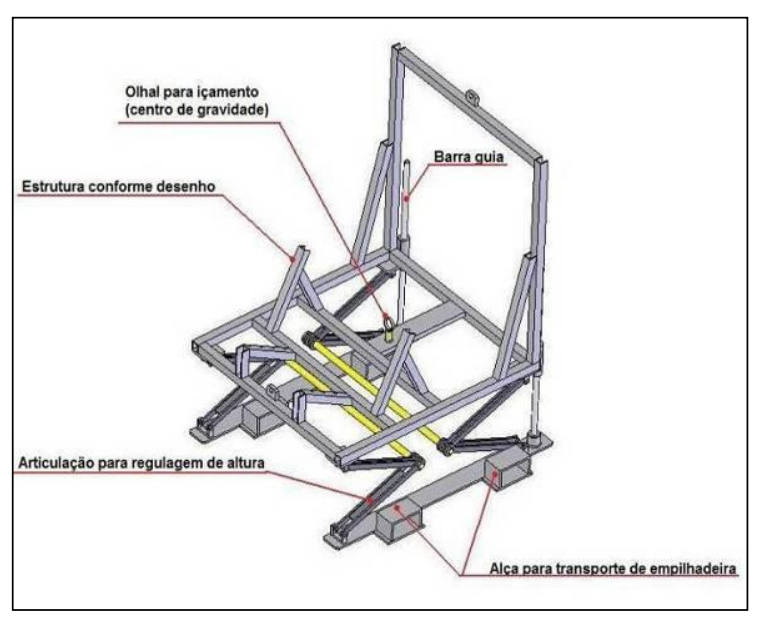

Figura 19 - Dispositivo regulável para posicionamento das peças

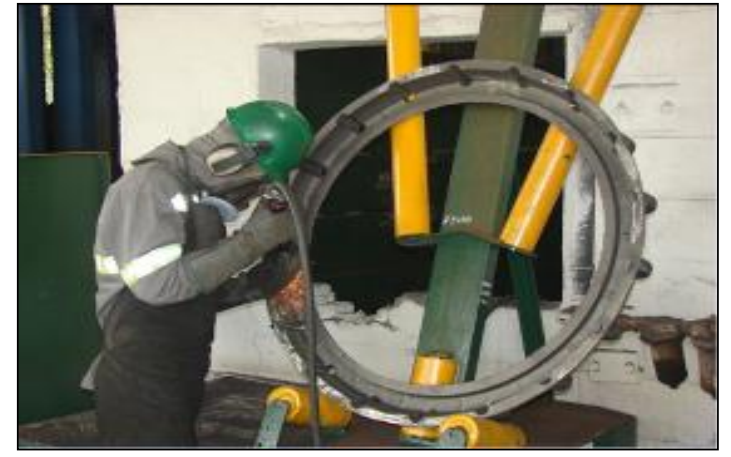

Figura 20 - Operador utilizando o dispositivo regulável para posicionamento das peças

O posicionamento das peças numa bancada pneumática regulável, conforme o modelo ilustrado na Figura 21, evita também que o operador adote posturas inadequadas.

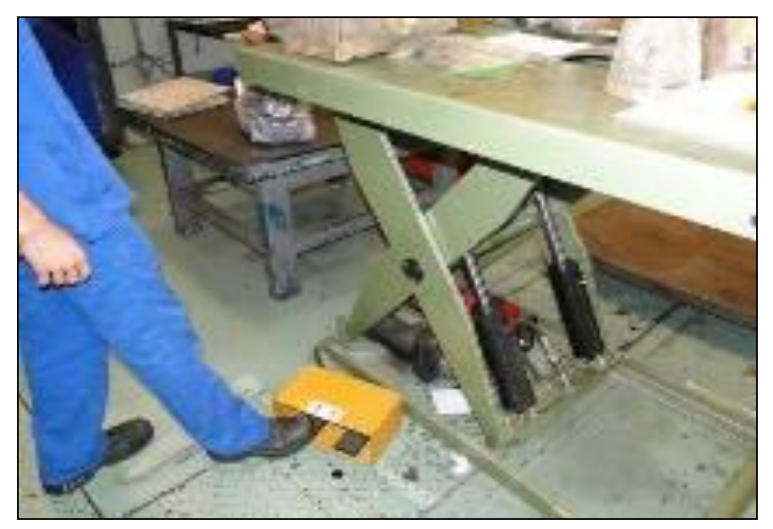

Figura 21 - Modelo de bancada pneumática regulável

Elaborou-se treinamento para capacitar os operadores no uso correto dos recursos e também conscientizá-los sobre a importância da adoção de posturas corretas na execução da atividade de acabamento de peças.

\section{Análise dos resultados}

A classificação das posturas após a implementação das melhorias está relacionada nos Quadros 3 e 4. 
Melhoria ergonômica em postos de trabalho do setor de acabamento de uma fundição através do método OWAS de análise de posturas

Quadro 3 - Classificação das posturas após a implementação das recomendações no posto mercado interno

\begin{tabular}{|c|c|c|c|c|}
\hline $\begin{array}{c}\text { POSTO DE } \\
\text { TRABALHO }\end{array}$ & POSTURA & FATORES & ÍNDICES & CLASSE \\
\hline \multirow{28}{*}{ Mercado interno } & \multirow{4}{*}{1} & DORSO: & 1 & \multirow{4}{*}{1} \\
\hline & & BRAÇO: & 2 & \\
\hline & & PERNAS: & 1 & \\
\hline & & CARGA: & 0 & \\
\hline & \multirow{4}{*}{2} & DORSO: & 1 & \multirow{4}{*}{1} \\
\hline & & BRAÇO: & 2 & \\
\hline & & PERNAS: & 1 & \\
\hline & & CARGA: & 0 & \\
\hline & \multirow{4}{*}{5} & DORSO: & 2 & \multirow{4}{*}{2} \\
\hline & & BRAÇO: & 1 & \\
\hline & & PERNAS: & 1 & \\
\hline & & CARGA: & 1 & \\
\hline & \multirow{4}{*}{7} & DORSO: & 1 & \multirow{4}{*}{1} \\
\hline & & BRAÇO: & 1 & \\
\hline & & PERNAS: & 1 & \\
\hline & & CARGA: & 1 & \\
\hline & \multirow{4}{*}{8} & DORSO: & 1 & \multirow{4}{*}{1} \\
\hline & & BRAÇO: & 1 & \\
\hline & & PERNAS: & 1 & \\
\hline & & CARGA: & 1 & \\
\hline & \multirow{4}{*}{12} & DORSO: & 2 & \multirow{4}{*}{2} \\
\hline & & BRAÇO: & 1 & \\
\hline & & PERNAS: & 1 & \\
\hline & & CARGA: & 0 & \\
\hline & \multirow{4}{*}{14} & DORSO: & 1 & \multirow{4}{*}{1} \\
\hline & & BRAÇO: & 1 & \\
\hline & & PERNAS: & 1 & \\
\hline & & CARGA: & 0 & \\
\hline
\end{tabular}

Quadro 4 - Classificação das posturas após a implementação das recomendações na linha carrossel

\begin{tabular}{|c|c|c|c|c|}
\hline $\begin{array}{c}\text { POSTO DE } \\
\text { TRABALHO }\end{array}$ & POSTURA & FATORES & ÍNDICES & CLASSE \\
\hline \multirow{36}{*}{ Linha Carrossel } & \multirow{4}{*}{3} & DORSO: & 1 & \multirow{4}{*}{1} \\
\hline & & BRAÇO: & 2 & \\
\hline & & PERNAS: & 1 & \\
\hline & & CARGA: & 0 & \\
\hline & \multirow{4}{*}{4} & DORSO: & 1 & \multirow{4}{*}{1} \\
\hline & & BRAÇO: & 2 & \\
\hline & & PERNAS: & 1 & \\
\hline & & CARGA: & 0 & \\
\hline & \multirow{4}{*}{6} & DORSO: & 2 & \multirow{4}{*}{2} \\
\hline & & BRAÇO: & 1 & \\
\hline & & PERNAS: & 1 & \\
\hline & & CARGA: & 1 & \\
\hline & \multirow{4}{*}{9} & DORSO: & 1 & \multirow{4}{*}{1} \\
\hline & & |BRAÇO: & 1 & \\
\hline & & PERNAS: & 1 & \\
\hline & & CARGA: & 0 & \\
\hline & \multirow{4}{*}{10} & DORSO: & 1 & \multirow{4}{*}{1} \\
\hline & & BRAÇO: & 1 & \\
\hline & & PERNAS: & 1 & \\
\hline & & CARGA: & 3 & \\
\hline & \multirow{4}{*}{11} & DORSO: & 1 & \multirow{4}{*}{1} \\
\hline & & BRAÇO: & 1 & \\
\hline & & PERNAS: & 1 & \\
\hline & & CARGA: & 1 & \\
\hline & \multirow{4}{*}{13} & DORSO: & 2 & \multirow{4}{*}{2} \\
\hline & & BRAÇO: & 1 & \\
\hline & & PERNAS: & 2 & \\
\hline & & CARGA: & 0 & \\
\hline & \multirow{4}{*}{15} & DORSO: & 1 & \multirow{4}{*}{1} \\
\hline & & BRAÇO: & 1 & \\
\hline & & |PERNAS: & 1 & \\
\hline & & CARGA: & 0 & \\
\hline & \multirow{4}{*}{16} & DORSO: & 1 & \multirow{4}{*}{1} \\
\hline & & BRAÇO: & 1 & \\
\hline & & |PERNAS: & 1 & \\
\hline & & CARGA: & 0 & \\
\hline
\end{tabular}

Após a implementação das recomendações, percebem-se melhoria na classificação das posturas e eliminação de $100 \%$ das posturas críticas (classes 3 e 4), conforme relacionado no Quadro 5 e no Gráfico 1. 
Quadro 5 - Classificação das posturas antes e depois da implementação das melhorias

\begin{tabular}{|c|c|c|c|}
\hline \multirow{2}{*}{$\begin{array}{l}\text { POSTO DE } \\
\text { TRABALHO }\end{array}$} & \multirow{2}{*}{ POSTURA } & \multicolumn{2}{|c|}{ CLASSE } \\
\hline & & ANTES & DEPOIS \\
\hline \multirow{7}{*}{ 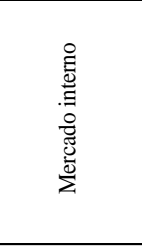 } & 1 & 3 & 1 \\
\hline & 2 & 2 & 1 \\
\hline & 5 & 2 & 2 \\
\hline & 7 & 2 & 1 \\
\hline & 8 & 2 & 1 \\
\hline & 12 & 2 & 2 \\
\hline & 14 & 2 & 1 \\
\hline \multirow{9}{*}{ 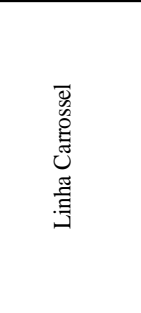 } & 3 & 4 & 1 \\
\hline & 4 & 2 & 1 \\
\hline & 6 & 2 & 2 \\
\hline & 9 & 2 & 1 \\
\hline & 10 & 3 & 1 \\
\hline & 11 & 2 & 1 \\
\hline & 13 & 2 & 2 \\
\hline & 15 & 3 & 1 \\
\hline & 16 & 1 & 1 \\
\hline
\end{tabular}

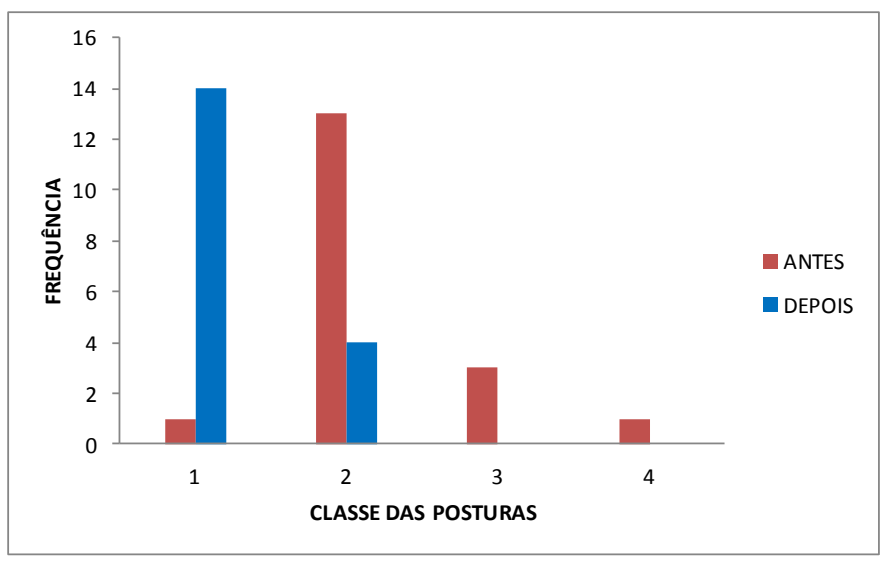

Gráfico 1 - Representação gráfica das posturas antes e depois da implementação das melhorias

\section{Considerações finais}

O método OWAS identificou a necessidade de intervenção em algumas tarefas necessárias para o acabamento das peças fundidas. $O$ posto de trabalho crítico em relação à questão da postura foi a linha carrossel, indicando a necessidade de intervenção urgente. Já no mercado interno algumas posturas requerem intervenções no curto prazo. A implementação das recomendações possibilitou a eliminação de $100 \%$ das posturas críticas, contribuindo para a preservação da saúde e o aumento do nível de satisfação dos trabalhadores e, também, da produtividade do setor de acabamento de peças.

\section{Referências}

GUÉRIN, F. et al. Compreender o trabalho para transformá-lo. 1. ed. São Paulo: Blucher/Fundação Vanzolini, 2001. 200 p.

IIDA, I. Ergonomia: projeto e produção. 2. ed. São Paulo: Blucher, 2005. 614 p.

LAVILLE, A. Ergonomia. São Paulo: EPU; EDUSP, 1977. 99 p.

WISNER, A. Por dentro do trabalho: ergonomia: Método \& técnica. São Paulo: FTD; Obore, 1987. $189 \mathrm{p}$.

Artigo selecionado entre os 10 melhores do VIII Encontro Mineiro de Engenharia de Produção - EMEPRO 2012. 